\title{
Blockchain-based multimedia security
}

Published online: 7 August 2021

() Springer Science+Business Media, LLC, part of Springer Nature 2021

Multimedia Tools and Applications gratefully acknowledges the editorial work of the scholars listed below on the special issue entitled "Blockchain-based Multimedia Security" (SI 1159T).

Of 26 papers submitted to this issue, 8 were eventually accepted after a stringent peer review process.

\section{Corresponding Guest Editor}

Yushu Zhang

Nanjing University of Aeronautics and Astronautics, China.

Email: yushu@ nuaa.edu.cn

\section{Guest Editors}

Ming Li

Henan University, China

Email: liming@htu.edu.cn

\section{Shangwei Guo}

Nanyang Technological University, Singapore

Email: shangwei.guo@ntu.edu.sg

\section{Weizhi Meng}

Technical University of Denmark, Denmark

Email: weme@dtu.dk

\section{Hongxiang Li}

University of Louisville, USA

Email: h.li@louisville.edu

Publisher's Note Springer Nature remains neutral with regard to jurisdictional claims in published maps and institutional affiliations. 